\title{
Optimal design parameters of drum's isolation system for a double-drum vibratory roller
}

\author{
Le Van Quynh', Vi Thi Phuong Thao ${ }^{2}$ Truong Tu Phong ${ }^{3}$ \\ ${ }^{1}$ Faculty of Automotive and Power Machinery Engineering, Thai Nguyen University of Technology, \\ Thai Nguyen, Vietnam \\ ${ }^{2}$ Faculty of International Training, Thai Nguyen University of Technology, Thai Nguyen, Vietnam \\ ${ }^{3}$ Center for Technical Practice, Thai Nguyen University of Technology, Thai Nguyen, Vietnam \\ ${ }^{1}$ Corresponding author \\ E-mail: ${ }^{1}$ lequynh@tnut.edu.vn, ${ }^{2} v i p h u o n g t h a o @ t n u t . e d u . v n,{ }^{3}$ phonghoa64@gmail.com
}

Received 27 April 2020; accepted 4 May 2020

DOI https://doi.org/10.21595/vp.2020.21445

Check for updates

Copyright $\circledast 2020$ Le Van Quynh, et al. This is an open access article distributed under the Creative Commons Attribution License, which permits unrestricted use, distribution, and reproduction in any medium, provided the original work is properly cited.

\begin{abstract}
The aim of this study is to propose an optimal design method for drum's isolation systems of a double-drum vibrating roller so that the ride comfort can be improved. A half-vehicle ride dynamic model is established based on the drum-ground interactions. The weighted root mean square (rms) of acceleration responses of the vertical and pitch vibrations of the vehicle body $\left(a_{w b}\right.$ and $\left.a_{w p h i}\right)$ according to the ISO 2631:1997(E) standard is chosen as objective functions. A genetic algorithm (GA) is applied for searching for the optimal design parameters of drum's isolation systems based on the objective functions. The study results indicate that the $a_{w b}$ and $a_{w p h i}$ values of GA optimal parameters reduce significantly in comparison with those of the original parameters of drum's isolation systems, which means that the performance optimization of drum's isolation systems is better than the original vehicle in improving the vehicle ride comfort.
\end{abstract}

Keywords: vibratory roller, drum, isolation system, design parameter, genetic algorithm, ride comfort.

\section{Introduction}

Vibratory roller operates and moves on various kinds of soil ground. The vibration excitation sources causing vehicle's body vibration are not only the excitations of the interaction between drum and deformation ground soil, but also the excitations of vibration drum and engine which are one of the main reasons for the driver fatigue and their working efficiency. The ride comfort of the vehicle has gained increasing attention and it is important to research on the dynamics of drum-frame and frame-cab systems and properties of the isolation system between them. The design parameters of cab's passive isolation system of a single drum vibratory roller were surveyed and evaluated its effect on ride comfort using a 3-D nonlinear dynamic model [1]. The influence of variations in the drum, cabin, seat, and rear-axle suspension properties on ride comfort was analyzed based on a 12-DOFs (degrees of freedom) pitch-plane ride dynamic model [2]. Even, the riding comfort was evaluated based on a nonlinear dynamics model of a single drum vibratory roller being operated under the different soil grounds [3]. To improve cab ride comfort of a vehicle, there were the optimal design and control solutions for cab's isolation system such as optimal design parameters for cab's auxiliary vibrations isolator [4] and cab's main isolation system [6], the PID-Fuzzy control for cab's isolation system [5]. The vibratory roller is usually not equipped with the suspension system to link the frame and vehicle axles, and it is important to reduce the transmission vibration from drums to frame. Drum's isolation systems plays an important role in reducing the transmission vibrations to the frame. The effect of the design parameters of drum's metal rubber isolation system of the double-drum vibratory roller on ride comfort was analyzed based on a 7-DOFs ride dynamic model [7]. The complex stiffness of the rubber absorber was optimized based on a 2-DOFs dynamic model and the objective functions such as the maximums of compact power product and minimal frame displacement [8]. A kind of MR damper was 
proposed and applied in drum's isolation systems to improve the comfort performance of the vibratory road roller [9].

This study presents an optimal design method for drum's isolation systems of a double-drum vibrating roller to improve the ride comfort considering a 4-DOFs half -vehicle ride dynamic model of a vehicle operating under different conditions. The genetic algorithm is applied for the optimal parameters of drum's isolation systems to minimize the values of the objective functions, thus the best comfort of the driver will be achieved. Finally, the optimal design parameters of drum's isolation systems are evaluated and compared to the ones of the original vehicle when the vehicle is operated under different conditions.

\section{Half-vehicle ride dynamic model}

A rubber isolation system between the drum and frame is shown in Fig. 1(a). A half -vehicle ride dynamic model with four degrees of freedom shown in Fig. 1(b) is considered for searching for the optimal design parameters of drum's isolation systems consisting of three main rigid bodies in which two drums and vehicle body are linked together by drum's metal rubber isolation systems.

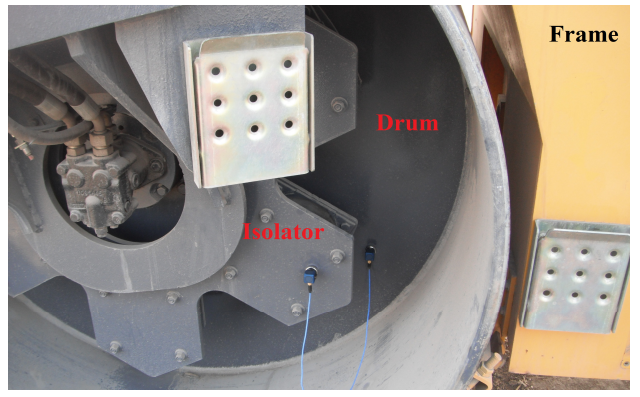

a) Side view of drum

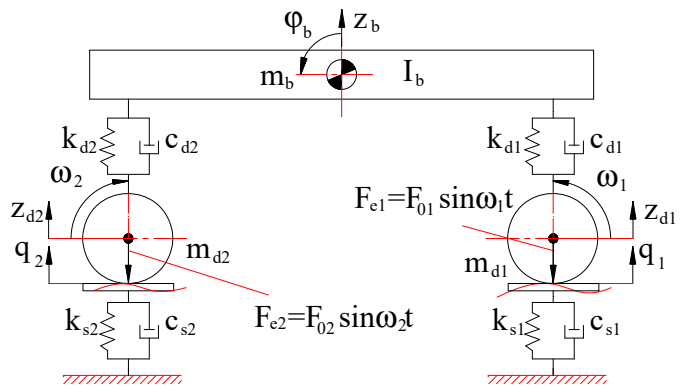

b) Half -vehicle ride dynamic model

Fig. 1. Double-drum vibrating roller

As shown in Fig. 1(b), $m_{d 1}, m_{d 2}$, and $m_{b}$ are the mass of the front drum, rear drum and vehicle body (including the frame, cab, and driver's seat), respectively; $k_{d 1}, k_{d 2}$, and $c_{d 1}, c_{d 2}$ are the stiffness and damping coefficients of the isolation system of the front and rear drums, respectively; $k_{s 1}, k_{s 2}$, and $c_{s 1}, c_{s 2}$ are the stiffness and damping coefficients of the elastic soil ground contact with the front and rear drums, respectively; $z_{d 1}, z_{d 2}$, and $z_{b}$ are the vertical displacement of the front drum, rear drum and the vehicle body, respectively; $\varphi_{b}$ is the pitch angle displacements of the vehicle body; $I_{b}$ is the moment of inertia with respect to the y of the vehicle body; $q_{1}$ and $q_{2}$ are the excitation of ground surface contact with the front and rear drums, $F_{1}=F_{01} \sin \omega_{1} t$ and $F_{2}=F_{02} \sin \omega_{2} t$.

The equations of motion for a double-drum vibrating roller using Newton's second law of motion are written in two cases.

\subsection{Case 1: vehicle moves into the workshop}

Vehicle wheel contacts and moves on types of road or ground surfaces such as rigid, flexible, soft, etc. [10]. The drum of vibratory roller in contact with the rigid road surface is the contact point which is considered in this study.

From the half-vehicle ride dynamic model, as shown in Fig. 1(b), the motion equations of the front vehicle body mass are written as follows:

$$
\begin{gathered}
m_{b} \ddot{z}_{b}=-\left[k_{d 1}\left(z_{b}+l_{1} \varphi_{b}-q_{1}\right)+c_{d 1}\left(\dot{z}_{b}+l_{1} \dot{\varphi}_{b}-\dot{q}_{1}\right)\right] \\
-\left[k_{d 2}\left(z_{b}-l_{2} \varphi_{b}-q_{2}\right)+c_{d 2}\left(\dot{z}_{b}-l_{2} \dot{\varphi}_{b}-\dot{q}_{2}\right)\right]
\end{gathered}
$$




$$
\begin{gathered}
I_{b} \ddot{\varphi}_{b}=\left[k_{d 2}\left(z_{b}-l_{2} \varphi_{b}-q_{2}\right)+c_{d 2}\left(\dot{z}_{b}-l_{2} \dot{\varphi}_{b}-\dot{q}_{2}\right)\right] l_{2} \\
-\left[k_{d 1}\left(z_{b}+l_{1} \varphi_{b}-q_{1}\right)+c_{d 1}\left(\dot{z}_{b}+l_{1} \dot{\varphi}_{b}-\dot{q}_{1}\right)\right] l_{1}
\end{gathered}
$$

where, $q$ is the random road surface excitation according to the International Standards Organization (ISO) 8608 [14].

\subsection{Case 2: vehicle operates in the workshop}

When vehicle works and compresses on many different types of properties of deformable ground soil such as the hysteretic force - deflection properties [6], the elasto-plastic properties [2], [13]., etc. The properties of deformable ground soil are linear by the stiffness and damping coefficients of the elastic soil ground. From the half -vehicle ride dynamic model as shown in Fig. 1(b), the motion equations of the front drum mass, rear drum mass and vehicle body mass are written as follows:

$$
\begin{aligned}
& m_{d 1} \ddot{z}_{d 1}=F_{01} \sin \omega_{1} t+\left[k_{d 1}\left(z_{b}+l_{1} \varphi_{b}-q_{1}\right)+c_{d 1}\left(\dot{z}_{b}+l_{1} \dot{\varphi}_{b}-\dot{q}_{1}\right)\right]-k_{s 1} z_{d 1}-c_{s 1} \dot{z}_{d 1}, \\
& m_{d 2} \ddot{z}_{d 2}=F_{02} \sin \omega_{2} t+\left[k_{d 2}\left(z_{b}-l_{2} \varphi_{b}-q_{2}\right)+c_{d 2}\left(\dot{z}_{b}-l_{2} \dot{\varphi}_{b}-\dot{q}_{2}\right)\right]-k_{s 2} z_{d 2}-c_{s 2} \dot{z}_{d 2}, \\
& m_{b} \ddot{z}_{b}=-\left[k_{d 1}\left(z_{b}+l_{1} \varphi_{b}-z_{d 1}\right)+c_{d 1}\left(\dot{z}_{b}+l_{1} \dot{\varphi}_{b}-\dot{z}_{d 1}\right)\right] \\
& \quad-\left[k_{d 2}\left(z_{b}-l_{2} \varphi_{b}-z_{d 2}\right)+c_{d 2}\left(\dot{z}_{b}-l_{2} \dot{\varphi}_{b}-\dot{z}_{d 2}\right)\right], \\
& I_{b} \ddot{\varphi}_{b}=\left[k_{d 2}\left(z_{b}-l_{2} \varphi_{b}-z_{d 2}\right)+c_{d 2}\left(\dot{z}_{b}-l_{2} \dot{\varphi}_{b}-\dot{z}_{d 2}\right)\right] l_{2} \\
& \quad-\left[k_{d 1}\left(z_{b}+l_{1} \varphi_{b}-z_{d 1}\right)+c_{d 1}\left(\dot{z}_{b}+l_{1} \dot{\varphi}_{b}-\dot{z}_{d 1}\right)\right] l_{1},
\end{aligned}
$$

\section{Optimal isolation parameters via genetic algorithm}

Assessing the off-road vehicle's ride comfort: There are four methods to objectively evaluate ride comfort such as the international standard ISO 2631, the British standard BS 6841, VDI 2057, and while average absorbed power (AAP) [16]. The weighted root mean square (rms) of acceleration responses based on the international standard ISO 2631 is used as the objective function which is determined by the formula:

$a_{w}=\left[\frac{1}{T} \int_{0}^{T} a^{2}(t) d t\right]^{1 / 2}$,

where $a(t)$ is the weighted acceleration (translational and rotational) as a function of time in $\mathrm{m} / \mathrm{s}^{2}$; $T$ is the duration of the measurements in s.

The genetic algorithm is a technique adapted from the evolutionary adaptation of biological populations by Darwinism. GA is a method of random optimization by mimicking the evolution of humans or organisms. Its idea is to simulate natural phenomena inheriting and fighting for survival. A simple genetic algorithm consists of the following steps: Step 1: Initialize a population of chromosome sequences; Step 2: Determine the target value for each corresponding chromosome; Step 3: Create new chromosomes based on genetic operators; Step 4: Eliminate low adaptive chromosomes; Step 5: Define the target function for new chromosomes and population inclusion. Step 6: Check whether the stop condition is satisfied. If the condition is right, get the best chromosome, and the algorithm stops; otherwise, go back to step 3.

Objective function: To improve the vehicle's ride comfort, the optimal parameters of drum's isolation systems are found out so that the values of the weighted root mean square (rms) of acceleration responses of cab's vertical vibration $\left(a_{w z}\right)$ and pitch vibration $\left(a_{w \varphi}\right)$ should be minimized:

$F(X)=w_{1}\left\{a_{w Z}(X)\right\}+w_{2}\left\{a_{w \varphi}(X)\right\} \rightarrow \min$,

where, $w_{n}(n=1,2)$ are the weighting coefficients of sub-objective functions such that $\left(w_{1}+\right.$ 
$\left.w_{2}=1\right) ; X=\left[k_{d 1}, k_{d 2}, c_{d 1}, c_{d 2}\right]$ is the design parameter vector of drum's isolation systems.

Boundary conditions: The objective function Eq. (8) must satisfy the following boundary conditions:

$$
\left\{\begin{array}{l}
0.9 \times 10^{6} \leq k_{d i} \leq 2.7 \times 10^{6} \\
2.5 \times 10^{3} \leq c_{d i} \leq 9 \times 10^{3}, \\
\left|z_{\text {bimax }}-z_{\text {dimax }}\right| \leq 1.2 \times 10^{-3}
\end{array} \quad i=1,2,\right.
$$

\section{Results and discussion}

In order to find out the values of the optimal parameters of drum's isolation systems of a double-drum vibrating roller, the differential equations of motion in case 1 and case 2 are solved through Matlab/Simulink environment with the initial vehicle design parameters as shown in Table 1. A program of genetic algorithm is written in Matlab to declare input parameters such as objective function Eq. (8) with $w_{1}=0.75, w_{2}=0.25$, boundary conditions Eq. (9), and GA parameters such as population size as 50 and generation as 200 , which called by Simulink module function using the sim function. When vehicle compacts on the original place with the parameters of the elastic soil grounds in Table 1 at both front and rear drums with the excitation frequencies of drums as $48 \mathrm{~Hz}$ (This condition is chosen for the optimal parameters because vehicle is often operates in this condition and it has the greatest impact on the drivers' health), the optimal values of the parameters of drum's isolation systems are obtained by GA method in comparison with the original parameters, as shown in Table 2.

Table 1. Parameters of a double-drum vibrating roller

\begin{tabular}{|c|c|c|c|c|c|}
\hline Parameters & Values & Parameters & Values & Parameters & Values \\
\hline$m_{d 1} / \mathrm{kg}$ & 2300 & $k_{d 2} /(\mathrm{N} / \mathrm{m})$ & $1803 \times 10^{3}$ & $F_{01} / \mathrm{N}$ & $128 \times 10^{3}$ \\
\hline$m_{d 2} / \mathrm{kg}$ & 2300 & $c_{d 2} /(\mathrm{Ns} / \mathrm{m})$ & 3990 & $F_{02} / \mathrm{N}$ & $96 \times 10^{3}$ \\
\hline$m_{b} / \mathrm{kg}$ & 3270 & $k_{s 1} /(\mathrm{N} / \mathrm{m})$ & $1 \times 10^{7}$ & $f_{1} / \mathrm{Hz}$ & $48 / 54$ \\
\hline$I_{b} / \mathrm{kg} \mathrm{m}{ }^{2}$ & 7811 & $c_{s 1} /(\mathrm{Ns} / \mathrm{m})$ & $210 \times 10^{3}$ & $f_{2} / \mathrm{Hz}$ & $48 / 54$ \\
\hline$k_{d 1} /(\mathrm{N} / \mathrm{m})$ & $1803 \times 10^{3}$ & $k_{s 2} /(\mathrm{N} / \mathrm{m})$ & $1.2 \times 10^{7}$ & $l_{1} / \mathrm{m}$ & 1.80 \\
\hline$c_{d 1} /(\mathrm{Ns} / \mathrm{m})$ & 3990 & $c_{s 2} /(\mathrm{Ns} / \mathrm{m})$ & $280 \times 10^{3}$ & $l_{2} / \mathrm{m}$ & 1.80 \\
\hline
\end{tabular}

Table 2. GA optimization parameters of drum's isolation systems

\begin{tabular}{|c|c|c|c|c|}
\hline Parameters & $k_{d 1} /(\mathrm{N} / \mathrm{m})$ & $c_{d 1} /(\mathrm{Ns} / \mathrm{m})$ & $k_{d 2} /(\mathrm{N} / \mathrm{m})$ & $c_{d 2} /(\mathrm{Ns} / \mathrm{m})$ \\
\hline Original values & $1803 \times 10^{3}$ & 3990 & $1803 \times 10^{3}$ & 3990 \\
\hline Optimal values by GA & $1017 \times 10^{3}$ & 2804 & $255 \times 10^{3}$ & 6130 \\
\hline
\end{tabular}

The performances of the GA are compared with the original parameters of drum's isolation systems when the vehicle operates at Case 2 with the excitation frequencies of drums as $48 \mathrm{~Hz}$, as shown in Fig. 2.

From the results of Fig. 2, we can determine the values of the weighted rms acceleration of the vertical vehicle body $\left(a_{w b}\right)$ and pitch angle of vehicle body $\left(a_{w p h i}\right)$ according to Eq. (7) are $0.6963 \mathrm{~m} / \mathrm{s}^{2}$ and $0.0810 \mathrm{rad} / \mathrm{s}^{2}$ with the original parameters of drum's isolation systems and $0.3497 \mathrm{~m} / \mathrm{s}^{2}$ and $0.0604 \mathrm{rad} / \mathrm{s}^{2}$ with GA optimal parameters of drum's isolation systems. The results show that the $a_{w b}$ and $a_{w p h i}$ values with GA optimal parameters respectively reduce by $99.11 \%$ and $34.11 \%$ in comparison with the original parameters of drum's isolation systems, which means that vehicle's ride comfort is improved significantly when the vehicle operates in this condition.

The optimized results of GA are compared to those of the original parameters of drum's isolation systems when the vehicle is operated at Case 2 with the different excitation frequencies of drums, as shown in Table 3. These results indicate that the $a_{w b}$ and $a_{w p h i}$ values of GA optimal parameters respectively reduce by $87.89 \%$ and $22.67 \%\left(f_{1}=54 \mathrm{~Hz}\right.$ and $\left.f_{2}=54 \mathrm{~Hz}\right), 42.03 \%$ 
and $42.65 \%\left(F_{10}=0\right.$ and $\left.f_{2}=48 \mathrm{~Hz}\right)$, and $34.53 \%$ and $34.92 \%\left(F_{10}=0\right.$ and $\left.f_{2}=54 \mathrm{~Hz}\right)$ in comparison with the original parameters of drum's isolation systems, which means that the ride comfort of the double-drum vibrating roller is improved significantly.

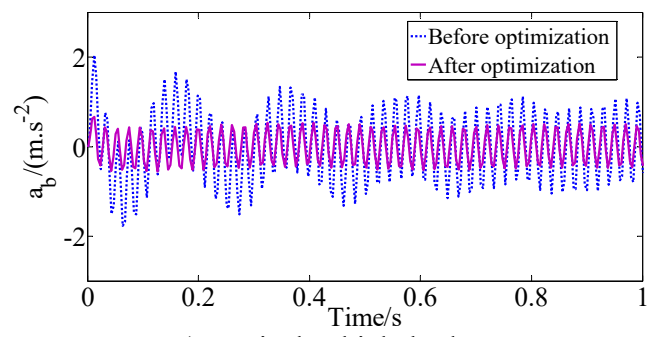

a) Vertical vehicle body

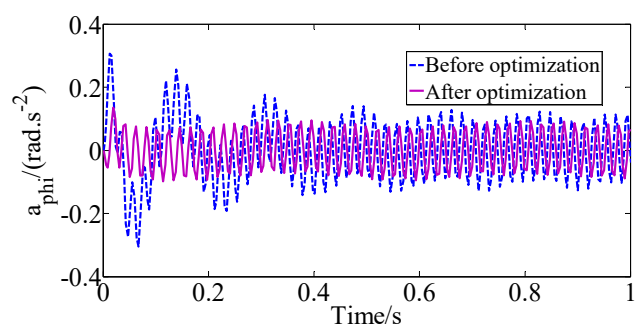

b) Pitch angle of vehicle body

Fig. 2. The comparison of acceleration responses of vehicle body at Case 2

Table 3. Comparison of optimized results at Case 2 with the different excitation frequencies

\begin{tabular}{|c|c|c|c|c|c|c|}
\hline \multirow{2}{*}{ Cases } & \multicolumn{2}{|c|}{$f_{1}=54 \mathrm{~Hz}$ and $f_{2}=54 \mathrm{~Hz}$} & \multicolumn{2}{c|}{$F_{10}=0$ and $f_{2}=48 \mathrm{~Hz}$} & \multicolumn{2}{c|}{$F_{10}=0$ and $f_{2}=54 \mathrm{~Hz}$} \\
\cline { 2 - 7 } & $a_{w z}\left(\mathrm{~m} \cdot \mathrm{s}^{-2}\right)$ & $a_{w p h i}\left(\mathrm{rad} \cdot \mathrm{s}^{-2}\right)$ & $a_{w z}\left(\mathrm{~m} . \mathrm{s}^{-2}\right)$ & $a_{w p h i}\left(\mathrm{rad} . \mathrm{s}^{-2}\right)$ & $a_{w z}\left(\mathrm{~m} . \mathrm{s}^{-2}\right)$ & $a_{w p h i}\left(\mathrm{rad} . \mathrm{s}^{-2}\right)$ \\
\hline Original parameters & 0.5723 & 0.0644 & 0.2984 & 0.2261 & 0.2466 & 0.1866 \\
\hline GA optimization & 0.3046 & 0.0525 & 0.2101 & 0.1585 & 0.1833 & 0.1383 \\
\hline Decrease \% & 87.89 & 22.67 & 42.03 & 42.65 & 34.53 & 34.92 \\
\hline
\end{tabular}

When the vehicle moves on the ISO class B road surface at the vehicle speed $v=15 \mathrm{~km} / \mathrm{h}$ (Case 1), the acceleration responses of the vertical vehicle body $\left(a_{b}\right)$ and the pitch angle of the vehicle body $\left(a_{p h i}\right)$ with GA optimal parameters in comparison with the original parameters of drum's isolation systems are shown Fig. 3. From the results of Fig. 3, we can determine the $a_{w b}$ and $a_{w p h i}$ values are $0.9822 \mathrm{~m} / \mathrm{s}^{2}$ and $0.8142 \mathrm{rad} / \mathrm{s}^{2}$ with the original parameters and $0.1960 \mathrm{~m} / \mathrm{s}^{2}$ and $0.1129 \mathrm{rad} / \mathrm{s}^{2}$ with GA optimal parameters of drum's isolation systems. The results show that $a_{w b}$ and $a_{w p h i}$ values with GA optimal parameters greatly reduce in comparison with the original parameters of drum's isolation systems, which means that the performance optimization of drum's isolation systems is better than the original isolation systems of drums in improving the ride comfort.

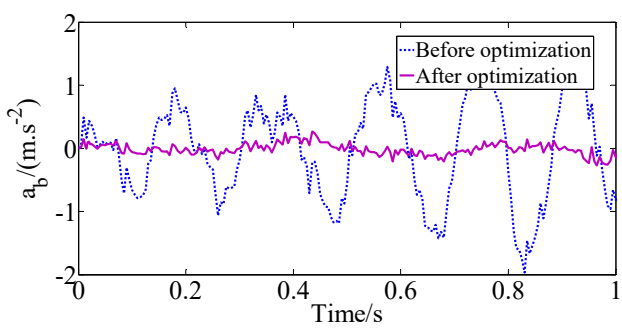

a) Vertical vehicle body

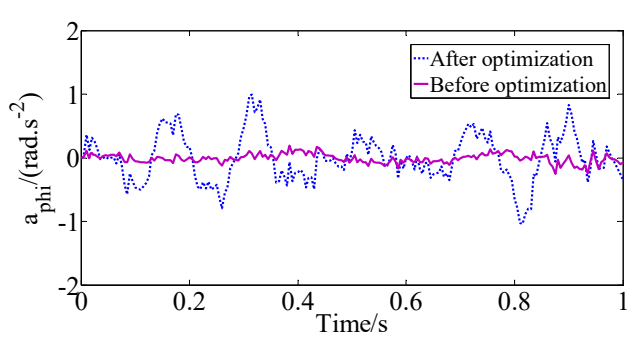

b) Pitch angle of vehicle body

Fig. 3. The comparison of acceleration responses of vehicle body at Case 1

Table 4. Comparison of optimized results at Case 1 with the different road surface conditions

\begin{tabular}{|c|c|c|c|c|c|c|}
\hline \multirow{2}{*}{ Cases } & \multicolumn{2}{|c|}{ ISO class C } & \multicolumn{2}{c|}{ ISO class D } & \multicolumn{2}{c|}{ ISO class E } \\
\cline { 2 - 7 } & $a_{w z}\left(\mathrm{~m} . \mathrm{s}^{-2}\right)$ & $a_{w p h i}\left(\mathrm{rad} . \mathrm{s}^{-2}\right)$ & $a_{w z}\left(\mathrm{~m}_{\mathrm{s}} \mathrm{s}^{-2}\right)$ & $a_{w p h i}\left(\mathrm{rad} . \mathrm{s}^{-2}\right)$ & $a_{w Z}\left(\mathrm{~m} . \mathrm{s}^{-2}\right)$ & $a_{w p h i}\left(\mathrm{rad} . \mathrm{s}^{-2}\right)$ \\
\hline Original parameters & 1.7673 & 1.4651 & 3.1023 & 2.5718 & 5.6108 & 4.6513 \\
\hline GA optimization & 0.3528 & 0.2033 & 0.6194 & 0.3569 & 1.1203 & 0.6456 \\
\hline Decrease \% & 400.94 & 620.66 & 400.86 & 620.59 & 400.83 & 620.46 \\
\hline
\end{tabular}

Similarly, the optimized results of GA are compared to those of the original parameters of drum's isolation systems when the vehicle moves at the vehicle speed $v=15 \mathrm{~km} / \mathrm{h}$ (Case 1 ) with 
the different road surface conditions, as shown in Table 4. These results indicate that the performance optimization of drum's isolation systems has been greatly improved the vehicle ride comfort. However, GA optimal parameters have not been considered for the ride performance on the frequency domain.

\section{Conclusions}

In this study, a half-vehicle ride dynamic model of a double-drum vibrating roller is established under different operating conditions for searching the optimal parameters for drum's isolation systems to improve the ride comfort. A genetic algorithm is applied for searching the optimal parameters of drum's isolation system order to minimize the $a_{w z}$ and pitch $a_{w \varphi}$ values in order to achieve the best comfort of a double-drum vibrating roller. The study results show that the $a_{w b}$ and $a_{w p h i}$ values with GA optimal parameters greatly reduce in comparison with the original parameters of drum's isolation systems, which means that vehicle's ride comfort is improved significantly. Also, the study results can provide the theoretical basis for the isolation system design of the vibrating rollers.

\section{References}

[1] Le Van Quynh, Thao V. T. P., et al. Influence of design parameters of cab's isolation system on vibratory roller ride comfort under the deformed ground surfaces. International Research Journal of Engineering and Technology (IRJET), Vol. 6, Issue 6, 2019, p. 1974-1978.

[2] Kordestani Rakheja, et al. Analysis of ride vibration environment of soil compactors. SAE International Journal of Commercial Vehicles, Vol. 3, Issue 1, 2010, p. 259-272.

[3] Le V. Q., Zhang J. R., et al. Ride comfort evaluation of vibratory roller under different soil ground. Transactions of the Chinese Society of Agricultural Engineering, Vol. 29, 2013, p. 39-47.

[4] Quynh L. V., Zhang J. R., et al. Vibration analysis and optimal design for cab's isolation system of vibratory roller. Advanced Materials Research, Vol. 199, 200, p. 936-940.

[5] Vanliem Nguyen, Renqiang Jiao, et al. Performance of PID-Fuzzy control for cab isolation mounts of soil compactors. Mathematical Models in Engineering, Vol. 5, Issue 4, 2019, p. 137-145.

[6] Le V. Q., Nguyen K. T. Optimal design parameters of cab's isolation system for vibratory roller using a multi-objective genetic algorithm. Applied Mechanics and Materials, Vol. 875, 2018, p. 105-112.

[7] Le Van Quynh, Thao V. T. P., et al. Study on influence of design parameters of drum's metal rubber isolation system of double vibratory roller on ride comfort. International Research Journal of Engineering and Technology (IRJET), Vol. 6, Issue 6, 2019, p. 1647-1651.

[8] Qin Sicheng, Chen Shuqing, et al. Analysis on the optimum mechanical property of an isolating System of Vibratory Roller. Transactions of the Chinese Society for Agricultural Machinery, Vol. 33, Issue 1, 2002, p. 77-79, (in Chinese).

[9] Liu S. N., Yan S. R., et al. Dynamic and control of vibratory road roller based on Magneto-Rheological semi-active damper. Advanced Materials Research, Vol. 479, Issue 481, 2012, p. 1200-1204.

[10] Quynh Le Van Vibration Study and Control Cab of Vibratory Roller. Southeast University, Nanjing, China, 2013.

[11] Sun Xiaojuan, Zhang Jianrun Performance of earth-moving machinery cab with hydraulic mounts in low frequency. Journal of Vibration and Control, Vol. 20, Issue 5, 2014, p. 724-735.

[12] Le V. Ride comfort analysis of vibratory roller via numerical simulation and experiment. DEStech Transactions on Engineering and Technology Research, 2017.

[13] Liem N. V., Run Z. J., et al. Vibration analysis and modeling of an off-road vibratory roller equipped with three different cab's isolation mounts. Shock and Vibration, Vol. 2018, 2018, p. 8527574.

[14] ISO 8068. Mechanical Vibration-Road Surface Profiles-Reporting of Measured Data. International Organization for Standardization, 1995.

[15] ISO 2631-1. Mechanical Vibration and Shock-Evaluation of Human Exposure to Whole-Body Vibration, Part I: General Requirements. The International Organization for Standardization, 1997.

[16] Els P. S., Theron N. J., et al. The ride comfort vs. handling compromise for off-road vehicles. Journal of Terramechanics, Vol. 44, Issue 4, 2007, p. 303-317. 